\title{
Spillover dynamics across price inflation and selected agricultural commodity prices
}

\author{
Mehmet Balcilar ${ }^{1}$ and Festus Victor Bekun $2,3^{*}$ (I)
}

\section{*Correspondence:}

fbekun@gelisim.edu.tr

${ }^{2}$ Faculty of Economics

Administrative and Social

Sciences, Istanbul Gelisim

University, Istanbul, Turkey

Full list of author information

is available at the end of the

article

\begin{abstract}
This article contributes to the existing empirical literature by examining the spillovers across price inflation and agricultural commodity prices for the case of Nigeria. To achieve this objective, we employ the Diebold and Yilmaz (Int J Forecast 28(1):57-66, 2012) spillover index. Subsequently, we examine the directional spillover, total spillover, and net spillover indexes. Further analysis to capture cyclical and secular movements was addressed with 40 months of subsamples via the rolling window analysis. Our empirical results, based on the monthly frequency data from January 2006 to July 2016 show that the total spillover effect was about 75\%. This suggests a high interconnectedness of the selected agricultural commodity prices and inflation. Further empirical findings shows that inflation, sorghum, soybeans, and wheat were net receivers while cocoa, barley, groundnut, maize, rice were net givers. We find a negative net spillover for price inflation, implying a net positive spillover from commodity prices to price inflation. Based on these outcomes, several inherent policy implications for the government administrators, farmers, investors and all stakeholders abound. For instance, the need for government officials to insulate the agricultural market from externalities for optimum prices stability is pertinent.
\end{abstract}

Keywords: Agricultural commodity prices, Inflation, VAR model, Forecast error variance, Price spillover, Nigeria

JEL Classification: C32, Q02, Q43

\section{Introduction}

Agricultural commodity prices in recent times have been experiencing an upward trend in record time (see Loening et al. 2009), since the 2006-2008 global food crisis. The spillover effect of the global food price surge in 2006-2008 has left most economies with the high inflation rate, large trade deficits and general poor macroeconomic environment especially in the developing economies. The explanation to this phenomenon is worthy of investigation so as to provide academicians, stakeholders and policymakers ample background as well as open opportunities for investors (Balcilar et al. 2014). The quest to underpin the rationale behind agricultural commodity price surge has been explored by several agricultural economists and interested researchers. Abbott et al. (2009) posited that the key drivers of hike in agricultural commodity prices are found in the huge synergy that exists among macroeconomic indicators. These indicators include oil prices,

(c) The Author(s) 2020. This article is licensed under a Creative Commons Attribution 4.0 International License, which permits use, sharing, adaptation, distribution and reproduction in any medium or format, as long as you give appropriate credit to the original author(s) and the source, provide a link to the Creative Commons licence, and indicate if changes were made. The images or other third party material in this article are included in the article's Creative Commons licence, unless indicated otherwise in a credit line to the material. If material is not included in the article's Creative Commons licence and your intended use is not permitted by statutory regulation or exceeds the permitted use, you will need to obtain permission directly from the copyright holder. To view a copy of this licence, visit http://creativeco mmons.org/licenses/by/4.0/. 
interest rate, exchange rate, unemployment, as well as the gap between agricultural productivity and increasing demand for food. In addition to the drivers of the increased agricultural commodity prices are policy decisions by decision/policy-makers, which go a long way to mold the destiny of an economy. However, the hike in oil price stands out among these factors. It is seen as the paramount driving force for high agricultural prices (see FAO 2008; Mitchell 2008 and OECD 2008).

Furthermore, there exists a burgeoning literature that explored the causal explanation of the global food price crisis (see Herndon 2008; Rosegrant 2008; Trostle 2008, Alola and Alola 2018). These studies have attributed the explanation to exchange rate volatility. For example, Trostle (2008) attributed the increase in agricultural food price to the weakness of the US dollar, which translates into a more competitive export market and thus spurs foreign demand for commodity prices volatility. Additionally, climate change is also expected to lower yield and increase variability in many production processes as are reflected in high food prices (Irz et al. 2012).

Previous empirical studies on the food-price inflation dynamics of an agricultural commodity like Baek and Koo (2010) and Lambert and Miljkovic (2010) for the case of United States especially have a common feature of examining the theme via graphical, descriptive and simulation approaches. In addition, to the best knowledge of the authors only the studies of Baek and Koo (2010), and Lambert and Miljkovic (2010) only examined the theme with cointegrated vector autoregressive model.

Thus, the motivation for this study is to fill the identified gap by examining the food price inflation spillover nexus for the case of Nigeria, which is known to be plagued by the high inflation rate. Until now, little is known regarding the casual explanation(s) to the theme for sub-Saharan Africa (SSA) especially Nigeria. Thus, to the best of the authors' knowledge, this study is novel for a few reasons. Firstly, the study contributes empirically to the food-inflation spillover nexus for a large array of major import agricultural commodity prices. Simply put that, our study seeks to investigate to what extent inflation spillover is explained by the selected agricultural commodity prices for the studied area. Secondly, our study contributes to the scanty empirical literature on the theme by leveraging on recently developed generalized forecast error variance decomposition methodology of Diebold and Yilmaz (hereafter DY) to examine the level of interdependencies among variables under consideration. Thirdly, we examined the rolling window analysis in order to explore both cyclical and secular movements to capture episodes that may be responsible for the magnitude of spillover for the selected agricultural commodity prices. The modified version of the DY approach in measuring spillovers has become popular in the empirics given that the technique itself is recent. Few studies have employed the technique (see Louzis 2012; Duncan and Kabundi 2013; Nishimura et al. 2015; Alola et al. 2019). Furthermore, in the African context empirically using the generalized vector auto-regressive (GVAR) methodology, multivariate generalized auto-regressive conditional heteroscedasticity (MGARCH) as estimation techniques, Katusiime (2019) investigated the relationship between oil and food price volatility in conjunction with some macroeconomic variables while considering financial stability for the case of Uganda. The empirical outcome from the GVAR and MGARCH shows low level of volatility spillover and market interconnectedness among the variables under review with just the exception of crises period. In Nigeria Fasanya and 
Akinbowale (2019) explored the interconnectedness among selected agricultural commodity crop prices and crude oil prices using the novel DY techniques. Empirical results from their study show that the returns spillover exhibits trend over the investigated period with no burst. On the other hand, the volatility spillover exhibits both trend and burst characteristics over sampled period.

Thus, based on the above highlights, the current study examines the dynamic spillover of price inflation across different cash crops in Nigeria over recent time-series dataset. The justification for this investigation is timely and informative to stakeholders in the agricultural business and policymakers after the 2006-2008 global food crisis. Empirical evidence shows high interdependencies among the selected agricultural commodity prices and price inflation. Thus, suggesting significant correlation among the variables. Further analysis reveals that a negative net spillover for price inflation, indicating a net positive spillover for the selected commodity prices to inflation. In addition, cocoa, barley, groundnut, maize, rice were observed as net givers of spillover effect. Thus, the attention of stakeholder and government administrators should be focused on net givers rather than net receivers like sorghum, soybeans, and wheat.

The layout of this study is structured as follows: Sect. 2 focuses on agricultural commodity prices and inflation: the peculiarity of Nigeria. Section 3 presents data and methodology while next Sect. 4 detail on results and discussions. Section 5 presents the rolling window analysis while concluding remarks and policy implications are reported in Sect. 6.

\section{Agricultural commodity price inflation dynamics: the peculiarity of Nigeria}

Nigeria is a country in the African continent, located in the western region of the continent, specifically in the sub-Saharan Africa (SSA) bordering around Benin republic, Niger and Cameroon with a population of over 170 million, Nigeria has the highest population in Africa. Nigeria is reputed for being the largest economy with the economy relying heavily on crude oil production as her source of foreign exchange earnings. The Nigeria economy is known to be an agrarian state with huge arable land for agricultural cultivation and production. Most of the crops produced such as cocoa, coffee, rubber tea, cotton, palm oil, corn, rice, sorghum, millet, cassava among others have export potential and value. Statistics have shown that despite the latent potential of Nigeria agricultural sector with large arable land and abundant natural resources, there has been a noticeable diminishing contribution of the sector to national prosperity. The empirical study of Alene et al. (2009) revealed that back in the 1960s the agricultural sector accounted for over $65-70 \%$ of total export. This statistics have declined in recent times to $40 \%$ in the 1970 s, and has trickled down to less than $20 \%$ in the 1990 s and much more in recent times. A further threat in the peak of world food price hike experienced from 2006 to 2008 . The aftermath is seen in general increase in agricultural commodity food market. The Nigerian economy over the years since the 1970s has witnessed high and volatile inflation. This inflation has spillover to the commodity market and the agricultural commodity market is not an exception, this was seen in the global 2006-2008 food crises and the effect has a great toll on the Nigerian food market severally with an obvious significant hike in agricultural commodities prices. The high inflation 
episodes experienced in the country is mainly driven by structural changes and macroeconomic indicators; further plausible explanation includes wage rise.

The selected agricultural crops for this study namely (groundnut, soybeans, sorghum, barley, maize, cocoa, rice, wheat) form the major crops in Nigeria. These crops are also known as cash crops given their inherent characteristics such as being a major staple food; they are the most produced and consumed in all parts of Nigeria. They also serve as a source of daily nutrition need giving their availability and affordability. In addition, these crops are the most traded agricultural commodities both domestically and internationally. Hence, they constitute the bulk of the commodity exports of Nigeria in the international market for grains. As noted by Akpan and Udoh (2009), the selected crops (rice, maize, millet, and sorghum) constitute a large fraction of staple food in Nigeria. This claim is further buttressed given that in the early 1980s precisely 1985 and 1995, cereals crops constitute almost 50\% of Nigeria's total food supply in terms of grain equivalent. To this extent, the need to investigate their price movements and spillover effect in regards to an inflation-prone country like Nigeria is crucial with the recent novel methodology of Diebold and Yilmaz (2012) spillover index. The knowledge about the pattern and magnitude of the spillovers among the selected crops will inform agricultural business portfolio managers for diversification of crop selection bundles.

\section{Methodology}

As earlier stated, our study leverages on the methodology of Diebold and Yilmaz to quantify the spillover between inflation and the selected agricultural commodity prices under review. The DY approach is unique given its less computational requirements, which helps in characterizing various episodes and events. The DY index is structured in a vector autoregressive (VAR) model and variance decomposition framework. The DY index is dated to 2009, as advanced by Diebold and Yilmaz (2009). However, the 2009 version of the DY index had the variance decomposition that is sensitive to the ordering of the variables as achieved by Cholesky factorization. The aforementioned procedure was flawed; in order to ameliorate the setback mentioned DY (2012) is an improvement on DY (2009) version with generalized VAR framework, which offers variance decomposition that is invariant to the ordering of variables after that of Koop et al. (1996) and Pesaran and Shin (1998).

Thus, this section provides the econometrics procedure for the current study to measure the spillovers from inflation to the selected major import prices of agricultural commodity prices. Our study empirically follows the recently developed Diebold and Yilmaz (2012) methodology, which is an improvement on the DY (2009). The DY (2012) approach is structured under (VAR) model framework, which is known to be invariant to variance decomposition ordering (Koop et al. 1996). The DY index reports four different spillovers indices namely; net spillovers, net pairwise spillovers, total spillovers and directional spillovers. DY methodology is based on a covariance stationary VAR:

$$
y_{t}=\Phi_{0}+\sum_{i=1}^{n} \Phi_{i} y_{t-i}+\varepsilon_{t}
$$

where $y_{t}=\left(y_{1 t}, y_{2 t}, \ldots, y_{n t}\right)^{\prime}$ is a vector of covariance stationary series $\Phi_{i}$, $i=0,1,2, \ldots, p$, denotes $(n \times n)$ matrix of parameters $\varepsilon_{t}$ is a $(n \times 1)$ vector of zero mean errors required to be independent and identically (iid) distributed with covariance 
matrix $\Sigma, \varepsilon_{t} \sim \operatorname{iid}(0, \Sigma)$. The moving average (MA) representation of the VAR in Eq. (1) is given as:

$$
y_{t}=\mu+\sum_{i=0}^{\infty} \Psi_{i} \varepsilon_{t-i}
$$

where $\Psi_{i}$ are $(n \times n)$ matrices recursively obtained from the equation $\Psi_{i}=\sum_{j=1}^{i} \Psi_{i-j} \Phi_{i}$, $i=1,2, \ldots, \mu$ is a $(n \times 1)$ vector of intercepts, and $A_{0}=I_{n}$, where $I_{n}$ is an identity matrix with dimension $n$. The spillover index is derived from Eq. (2) that forms the variance decomposition. Prior to the presentation of the diverse indices, the following pertinent notices are crucial:

(a) Own variance shares are described as the fractions of the $H$-steps-ahead error variance in forecasting $y_{i t}$ that are attributed to shocks for $y_{i t}, i=1,2, \ldots, n$.

(b) Cross-variance spillovers are described as a share of the $H$-step-ahead error variance forecasting $y_{i t}$ that are accrued to $y_{j t}, j=1,2, \ldots, n$, shock to such that $i \neq j$.

(c) Based on the Koop et al. (1996) generalized VAR framework, $H$-step-ahead forecast error variance decomposition represented by $\theta_{i j}^{g}(H)$ is obtained by

$$
\theta_{i j}^{g}(H)=\frac{\sigma_{i j}^{-1} \sum_{h=1}^{H-1}\left(e_{i}^{\prime} \Psi_{h} e_{j}\right)^{2}}{\sum_{h=1}^{H-1}\left(e_{i}^{\prime} \Psi_{h} \Sigma \Psi_{h}^{\prime} e_{j}\right)^{2}},
$$

where $\sigma_{i j}$ depicts the standard error of $\varepsilon_{t}$ for $j$ th equation and $e_{i}$ is the selection vector, with one as the $i$ th element and zeros otherwise.

(d) Given that the sum of the contribution to the variance of the forecast error is not equal to one, which implies that $\sum_{j=1}^{n} \theta_{i j}^{g}(H) \neq 1$; Diebold and Yilmaz (2012) approach normalizes each entry of the variance decomposition matrix. The normalized $H$-step-ahead forecast error variance decomposition by Koop et al. (1996) is given by

$$
\widetilde{\theta}_{i j}^{g}(H)=\frac{\theta_{i j}^{g}(H)}{\sum_{j=1}^{n} \theta_{i j}^{g}(H)},
$$

where $\sum_{j=1}^{n} \widetilde{\theta}_{i j}^{g}(H)=1$ and $\sum_{i, j=1}^{n} \widetilde{\theta}_{i j}^{g}(H)=n$ by the construction.

Thus, given these preludes, the total spillover index is deduced as:

$$
S^{g}(H)=\frac{\sum_{i, j=1, i \neq j}^{n} \widetilde{\theta}_{i j}^{g}(H)}{\sum_{i, j=1}^{n} \widetilde{\theta}_{i j}^{g}(H)}=\frac{\sum_{i, j=1, i \neq j}^{n} \widetilde{\theta}_{i j}^{g}(H)}{N} .
$$

Equation (5) captures the total spillovers index. For our case, total spillover across 8 selected agricultural commodity prices and the consumer price inflation. The DY (2012) technique offers the opportunity to explore the flow of direction of spillover across inflation and the selected agricultural commodity prices under review. The directional spillover are of two divide namely "to" directional spillover and "from" directional spillover. The "to" directional spillover measure whether spillovers transmitted by all other variables to the considered variable. While "from" directional spillover accounts for spillovers 
received by one variable from all other variables. In this study case, we consider directional spillover received from inflation to the agricultural commodities is investigated and vice versa.

The "to" directional spillover is computed as

$$
S_{i .}^{g}(H)=\frac{\sum_{j=1, j \neq i}^{n} \widetilde{\theta}_{i j}^{g}(H)}{\sum_{i, j=1}^{n} \widetilde{\theta}_{i j}^{g}(H)}=\frac{\sum_{j=1, j \neq i}^{n} \widetilde{\theta}_{i j}^{g}(H)}{N},
$$

while the directional spillover "from" is represented as and computed by the index given as:

$$
S_{i .}^{g}(H)=\frac{\sum_{j=1, j \neq i}^{n} \widetilde{\theta}_{j i}^{g}(H)}{\sum_{i, j=1}^{n} \widetilde{\theta}_{i j}^{g}(H)}=\frac{\sum_{j=1, j \neq i}^{n} \widetilde{\theta}_{j i}^{g}(H)}{N} .
$$

Thus, net spillover can be computed as the difference between the "to" and "from" directional spillover indices. It is described as:

$$
S_{i}^{g}(H)=S_{\cdot i}^{g}(H)-S_{i \cdot}^{g}(H) .
$$

Our study considers a first order 9-variable VAR with 10-step-ahead forecast. Adequate diagnostic analyses are offered to affirm robustness of our estimation to avoid spurious analysis. The current study seek to leverage on the novel DY methodology to explain the current theme comprehensively to show spillovers to agricultural prices from price inflation and further illustrates consequences on food prices market.

\section{Data and empirical results}

This section proceeds with preliminary analysis on the selected agricultural commodity listed in Table 1. To ascertain their statistical properties, our study leverage on monthly frequency data set from 2006M1 to 2016M7, which was retrieved from the African Development Bank (ADB) database.

The summary statistics of the interest variables and correlation analysis are reported in Table 2. Noteworthy here is that all variables investigated are seasonally adjusted via census X-13 additive outlier approach. The graphical plot of the underlined variables is rendered in Fig. 1, which shows the characterization of the series over the sampled

Table 1 Data description

\begin{tabular}{lc}
\hline Variables & Description \\
\hline Cocoa & $($ cents $/ \mathrm{kg})$ \\
Groundnut & $\$ / \mathrm{mt}$ \\
Soybeans & $\$ / \mathrm{mt}$ \\
Barley & $\mathrm{cents} / \mathrm{kg}$ \\
Maize & $\$ / \mathrm{mt}$ \\
Sorghum & $\$ / \mathrm{mt}$ \\
Rice & $\$ / \mathrm{mt}$ \\
Wheat & $\$ / \mathrm{mt}$ \\
CPI (Inflation) & Index \\
\hline
\end{tabular}


Table 2 Summary statistics and correlation coefficient estimates

\begin{tabular}{llllllllll}
\hline & CO & GN & SB & BA & MA & SO & RI & WH & CPI \\
\hline Panel A: descriptive statistics & & & & & & & & \\
Mean & 5.551 & 7.190 & 6.100 & 5.137 & 5.278 & 5.245 & 6.123 & 5.436 & 4.752 \\
Median & 5.594 & 7.214 & 6.120 & 5.170 & 5.183 & 5.276 & 6.132 & 5.449 & 4.773 \\
Maximum & 5.878 & 7.920 & 6.501 & 5.575 & 5.816 & 5.781 & 6.765 & 6.052 & 5.319 \\
Minimum & 5.010 & 5.329 & 5.542 & 4.618 & 4.619 & 4.558 & 5.656 & 4.943 & 4.211 \\
Std. dev. & 0.225 & 0.484 & 0.239 & 0.252 & 0.295 & 0.267 & 0.247 & 0.244 & 0.315 \\
Skewness & -0.837 & -2.081 & -0.683 & -0.324 & 0.035 & -0.270 & -0.071 & -0.003 & -0.077 \\
Kurtosis & 2.786 & 9.031 & 2.830 & 2.131 & 2.413 & 2.526 & 2.506 & 2.196 & 1.732 \\
Jarque-Bera & 15.065 & 284.138 & 10.034 & 6.209 & 1.846 & 2.738 & 1.395 & 3.418 & 8.639 \\
Probability & 0.001 & 0.000 & 0.007 & 0.045 & 0.397 & 0.254 & 0.498 & 0.181 & 0.013 \\
Sum & 705.016 & 913.126 & 774.733 & 652.394 & 670.291 & 666.126 & 777.623 & 690.383 & 603.512 \\
Sum sq. dev. & 6.404 & 29.534 & 7.191 & 8.033 & 10.979 & 8.986 & 7.681 & 7.515 & 12.489 \\
Observations & 127 & 127 & 127 & 127 & 127 & 127 & 127 & 127 & 127
\end{tabular}

Panel B: correlation coefficient estimates

\begin{tabular}{|c|c|c|c|c|c|c|c|c|c|}
\hline $\mathrm{CO}$ & 1 & & & & & & & & \\
\hline$T$-stat & - & & & & & & & & \\
\hline$P$ value & - & & & & & & & & \\
\hline No. Obs & 127 & & & & & & & & \\
\hline GN & 0.150 & 1 & & & & & & & \\
\hline$T$-stat & 1.701 & - & & & & & & & \\
\hline$P$-value & 0.091 & - & & & & & & & \\
\hline No. Obs & 127 & 127 & & & & & & & \\
\hline SB & 0.512 & 0.337 & 1 & & & & & & \\
\hline T-stat & 6.664 & 4.007 & - & & & & & & \\
\hline$P$-value & 0.000 & 0.000 & - & & & & & & \\
\hline No. Obs & 127 & 127 & 127 & & & & & & \\
\hline BA & 0.218 & 0.244 & 0.668 & 1 & & & & & \\
\hline$T$-stat & 2.502 & 2.814 & 10.048 & - & & & & & \\
\hline$P$-value & 0.014 & 0.006 & 0.000 & - & & & & & \\
\hline No. Obs & 127 & 127 & 127 & 127 & & & & & \\
\hline MA & 0.309 & 0.233 & 0.874 & 0.798 & 1 & & & & \\
\hline T-stat & 3.639 & 2.678 & 20.090 & 14.828 & - & & & & \\
\hline$P$-value & 0.000 & 0.008 & 0.000 & 0.000 & - & & & & \\
\hline No. Obs & 127 & 127 & 127 & 127 & 127 & & & & \\
\hline SO & 0.398 & 0.176 & 0.790 & 0.792 & 0.894 & 1 & & & \\
\hline$T$-stat & 4.853 & 1.998 & 14.415 & 14.494 & 22.327 & - & & & \\
\hline$P$-value & 0.000 & 0.048 & 0.000 & 0.000 & 0.000 & - & & & \\
\hline No. Obs & 127 & 127 & 127 & 127 & 127 & 127 & & & \\
\hline $\mathrm{Rl}$ & 0.450 & 0.236 & 0.744 & 0.452 & 0.689 & 0.539 & 1 & & \\
\hline T-stat & 5.632 & 2.714 & 12.465 & 5.669 & 10.615 & 7.152 & - & & \\
\hline$P$-value & 0.000 & 0.008 & 0.000 & 0.000 & 0.000 & 0.000 & - & & \\
\hline No. Obs & 127 & 127 & 127 & 127 & 127 & 127 & 127 & & \\
\hline WH & 0.252 & 0.356 & 0.853 & 0.749 & 0.822 & 0.763 & 0.461 & 1 & \\
\hline T-stat & 2.907 & 4.263 & 18.265 & 12.651 & 16.167 & 13.212 & 5.800 & - & \\
\hline$P$-value & 0.004 & 0.000 & 0.000 & 0.000 & 0.000 & 0.000 & 0.000 & - & \\
\hline No. Obs & 127 & 127 & 127 & 127 & 127 & 127 & 127 & 127 & \\
\hline CPI & 0.651 & 0.011 & 0.393 & 0.340 & 0.342 & 0.499 & 0.163 & 0.224 & 1 \\
\hline T-stat & 9.591 & 0.124 & 4.784 & 4.049 & 4.063 & 6.429 & 1.853 & 2.569 & - \\
\hline$P$-value & 0.000 & 0.902 & 0.000 & 0.000 & 0.000 & 0.000 & 0.066 & 0.011 & - \\
\hline No. Obs. & 127 & 127 & 127 & 127 & 127 & 127 & 127 & 127 & 127 \\
\hline
\end{tabular}


Table 2 (continued)

All the above-mentioned series were log transformed as well as seasonally adjusted with the exception of CPI with census $\mathrm{X}-13$ with additive outlier option type. WH, SB, SO, RI, MA, BA, GA, and CO denote wheat, soybean, sorghum, rice, maize, barley, groundnut, and cocoa, respectively

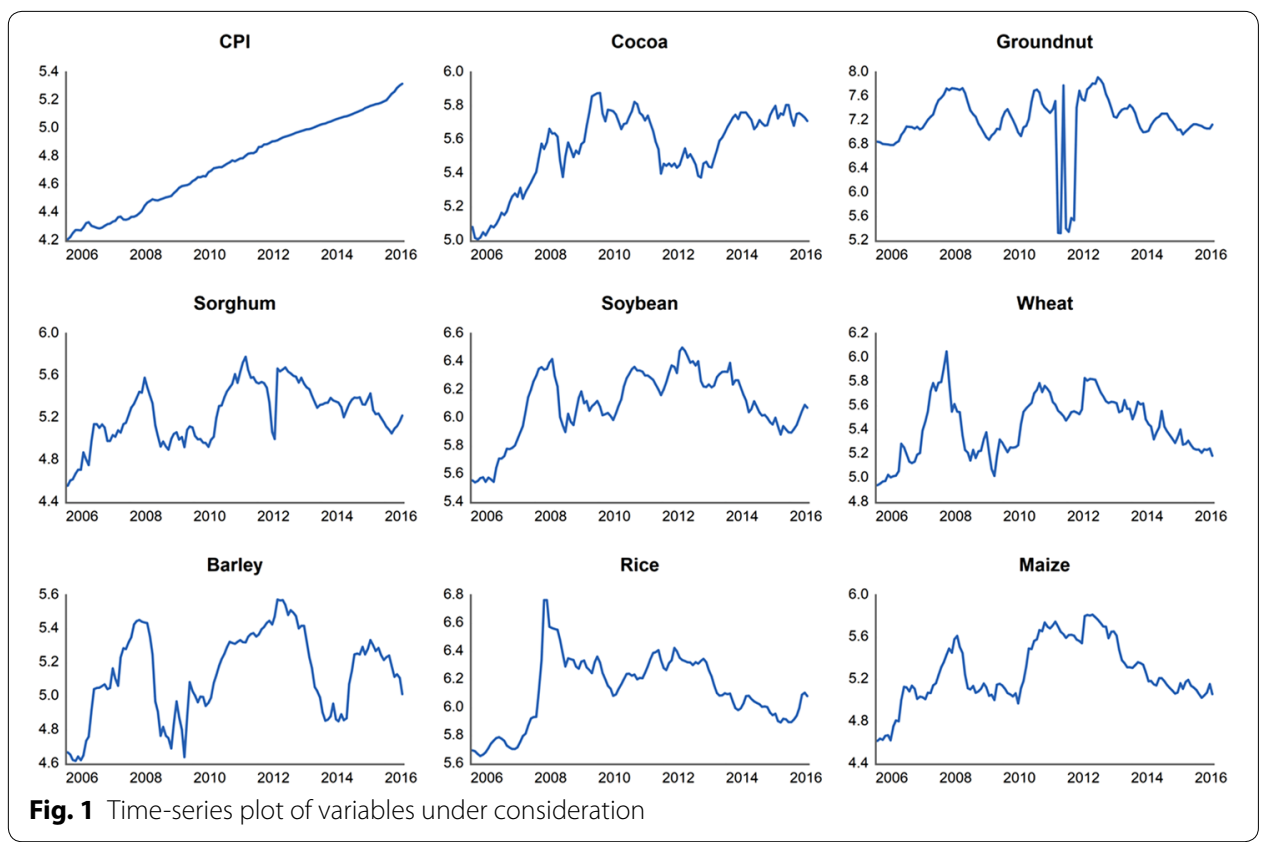

period. Summary statistics given in Panel A of Table 2 show that all variable has an average between 5.2 and 6.2 with all series negatively skewed with the exception of maize. Thus, indicating non-normality across the variables, that is affirmed by the heavy tail exhibited by the series as reported by kurtosis. Jarque-Bera (JB) probability corroborates the non-normality distribution across the mean values of the variables being considered for our study for the period considered. The JB probability is rejected for cocoa, groundnut, soybean and barley crops while for JB probability could not be rejected for the case of maize, sorghum, rice, and CPI. Panel B of Table 2 renders the correlation relationship between the pairs of variables. Observed is a positive significant relationship is imminent. For example, the positive significant relationship is observed between cocoa and coffee, a similar trend is seen among barley and soybean.

\subsection{Spillover analysis}

This section focuses on the analysis of DY results. Using VAR(1) model chosen by the Schwarz Bayesian information criterion (SBIC) as the optimal and most parsimonious one, we perform the spillover analysis for a 10-step $(H=10)$ forecast error variance decomposition following the majority of the previous studies (Salisu et al. 2018; Louzis 2012; Diebold and Yilmaz 2009, 2012). Table 3 presents the lag selection criterion and this is necessary to choose the most parsimonious and appropriate model. This is essential in our study in order not to estimate misleading regressions and analysis.

The DY methodology is divided into two main sub-groups namely; (i) spillover analysis and (ii) rolling window analysis. The spillover analysis renders a single scalar 
Table 3 Lag selection criterion

\begin{tabular}{lllllll}
\hline Lag & Log L & LR & FPE & AIC & SC & HQ \\
\hline 0 & 399.9509 & NA & $1.13 e-14$ & -6.570603 & -6.360417 & -6.485253 \\
1 & 1664.351 & 2316.295 & $2.62 \mathrm{e}-23^{*}$ & -26.45967 & $-24.35781^{*}$ & $-25.60617^{*}$ \\
2 & 1725.735 & 103.1676 & $3.72 \mathrm{e}-23$ & -26.13000 & -22.13647 & -24.50836 \\
3 & 1780.613 & 83.93005 & $6.10 \mathrm{e}-23$ & -25.69097 & -19.80577 & -23.30117 \\
4 & 1844.075 & 87.46122 & $9.15 \mathrm{e}-23$ & -25.39622 & -17.61935 & -22.23828 \\
5 & 1911.276 & 82.44795 & $1.40 \mathrm{e}-22$ & -25.16430 & -15.49576 & -21.23821 \\
6 & 2005.404 & 101.2466 & $1.51 \mathrm{e}-22$ & -25.38494 & -13.82472 & -20.69070 \\
7 & 2122.521 & 108.2593 & $1.30 \mathrm{e}-22$ & -25.99194 & -12.54005 & -20.52956 \\
8 & 2259.367 & $105.7974^{*}$ & $1.00 \mathrm{e}-22$ & $-26.93054^{*}$ & -11.58698 & -20.70001 \\
\hline
\end{tabular}

LR represents sequential modified LR statistic, Log $L$ is the log likelihood, FPE is the final prediction error, AIC is the Akaike Information Criterion, SIC is the Schwarz Information Criterion and HQ is the Hannan-Quinn Information Criterion, respectively, while *depicts the optimum lag selected

that are fixed values for the various indices over the considered period based on the full sample estimates. Thus, it helps to capture aggregate spillovers over the interest period. On the other hand, the rolling window analysis becomes handy where unprecedented events or episodes are observed. The rolling window helps to account for a deeper and intuitive dynamics. Both divides of the DY index complement each other where the rolling window stretches beyond the scaler values to unveil the cyclical and secular movement of spillovers from a particular period to another.

The spillover estimation as reported in Table 4 are computed for the entire sample period based on VAR(1) for 9 variables with 10-step-ahead forecast error. The table has both "contribution to others" derived from the sum of the off-diagonal column and in same fashion "contribution from others" which is the sum of off-diagonal of row. Both aforementioned directional spillovers could either be "directional spillovers to others" and "directional spillover from other" represents the contribution from others all available in Table 4. Therefore, each value on Table 4 with the exclusion of the main diagonal value captures individual agricultural commodity prices spillover and inflation to the forecast error variance of the other commodity prices under consideration. Similarly, in the same fashion, each value in each row, with the exception of the main diagonal values helps to captures the amount of contribution of other agricultural commodity price spillover and inflation to the forecast error variance over the period under review.

There exists similarity between the spillover table and the input-output table as they share common features to show among investigated variables impact of shock and identify absorber and transmitter of shock among interest variables. Also, the spillover table also displays net spillover, which is computed by the difference between contributions from others, and contribute to others or vice versa (see Eq. 8 in the methodology section). Noteworthy here is that a positive value depicts that the commodity in our study case the various agricultural commodity prices and inflation has a greater influence on another commodity than it receives from them; thus makes the commodity less vulnerable to external shock. On the other hand, a negative magnitude implies that the commodity is a net receiver that is more vulnerable, that is responsive to external shock from other commodities and inflation. The total spillover index is a lump sum value computed 


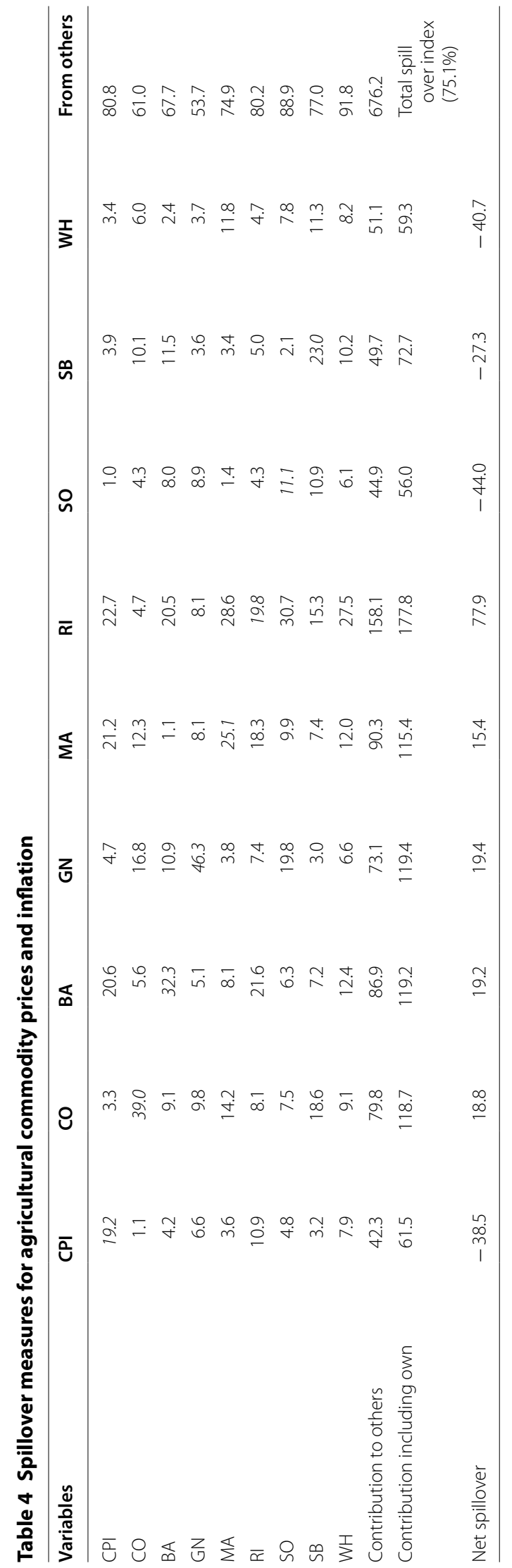


by the aggregate of contributions to others as a percentage of the sum of contribution including own shock. Thus, the total spillover offers the various directional spillover numbers into a single index number in percentage terms.

Table 4 displays spillover calculations for the selected agricultural commodity prices under review and inflation for the full sample period.

The empirical results show that the total spillover index is $75.1 \%$ indicating a high level of interconnectedness among the investigated commodities prices and inflation. In other words, well two-thirds of the total forecast error variances across all investigated agricultural commodity can be attributed to a spillover effect. That is, overwhelming, over $75 \%$ of total variance forecast error during the investigated period is explained by shocks across the variance errors while idiosyncratic shocks accounts for $24.9 \%$ in our estimation.

The examination of the individual directional spillovers measures from other (row) excluding main diagonal shows that rice recorded the highest dedicated contribution to forecasting error variance of price inflation among the investigated commodities with $22.7 \%$ seconded by maize with about $22.2 \%$. That is, shocks on rice are more likely to spill over to the other commodities as well as the general price inflation. Thus, shocks to rice exhibit more likely to affect the pattern of another commodity in the investigated area with $158.1 \%$ of the contribution to others and net spillover of $77.9 \%$. Insightful in our results is that rice possesses the greater impact on the forecast error variance (column) with $10.9 \%$ distantly followed by cocoa and soybeans with $3.2 \%$ and $1.1 \%$, respectively. A similar analysis holds for the other commodity prices. On the whole contribution from other records significantly high values amidst all commodity and inflation buttressing the high connectedness already established with wheat ranking highest followed by soybean, inflation and groundnut are least in this order. In other words, shocks to other commodity account for greater forecast percentage of the forecast error variance of wheat, soybean, rice, soybean, cocoa, and CPI than their own shocks while forecast error variance of groundnut and barley are considerably explained by their own shock. Thus, suggestively wheat is more vulnerable to shocks relatively to other variables investigated in the current study. These findings further give credence to the role cereal crops plays in the study area and global food commodity market. Finally, on the spillover table is the net spillovers section on the tail bottom of Table 4 . The net spillover shows that 4 of the investigated variables are net receivers (CPI and sorghum, soybean and wheat) while the remainder is a net giver. Thus, for the policy decision by government administrators are encouraged to pay more attention to major actors in the markets that are net givers, as shocks to such market will be transmitted to others. We find that price inflation is net spillover receiver, that is a $38.5 \%$ net spillover from the 8 commodities to CPI inflation, implying a commodity inflation pass-through to price inflation.

\section{Rolling sample analysis}

A glimpse on the "average" spillover effects over the full sample period is rendered by spillover analysis. Diebold and Yilmaz $(2009,2012,2014)$ expressed that the full sample spillover measures cannot explicitly reflect important secular and cyclical movement in spillovers. On these premise of the aforementioned bottlenecks, we offer a rolling window framework that allows for time-varying spillover indices, using a 40-month 
subsample in order to circumvent the earlier shortcomings of the spillover index, it is pertinent the rolling window analysis also help to holistically capture some episodes and events over the interest period under consideration. First, it is a matter of importance to check the way and pattern with which inflation spilled over to the agricultural commodities involved and how spillovers from the agricultural commodities affected inflation. Figure 2 reveals the presence of strong interdependence between inflation and other agricultural commodities. However, it is obvious that directional spillovers from inflation depict more several high episodes than directional spillovers to inflation. This being evident even from the spillover table as inflation exerts great influence on the agricultural commodities.

Further analysis from Fig. 3 affords us to investigate the net transmitters and receivers and their input to total spillovers via the net directional spillover. Our study identifies groundnut, rice, and inflation net spillovers as net receivers as they showed negative patterns between 2007 and 2016. On the other hand, soybean and maize were identified as net transmitters while wheat, cocoa sorghum, and barley exhibited mixed patterns. Interestingly, during the electioneering process in 2011, wheat was considered net receiver coincidentally, sorghum, barley, and cocoa were net spillover transmitter. It is worthy of mention that all investigated agricultural commodities exhibited significant spillovers after 2006-2008 food crises as well as global financial crunch period.

We proceed to plot the total spillover index as presented in Fig. 4, the total spillovers start with about $89 \%$ and maintained such level before hitting around $85 \%$ as a result of the global meltdown crisis at that time. Immediately after 2008, the spillovers fluctuated between 80 and $85 \%$. In 2009, there were high indications that oil and gas could no longer sustain the economy even as the petroleum subsidies became almost equal to the capital budget, hence, strong indications were made to deregulate the sector as well diversify the economy by giving special attention to the agricultural sector. This stern

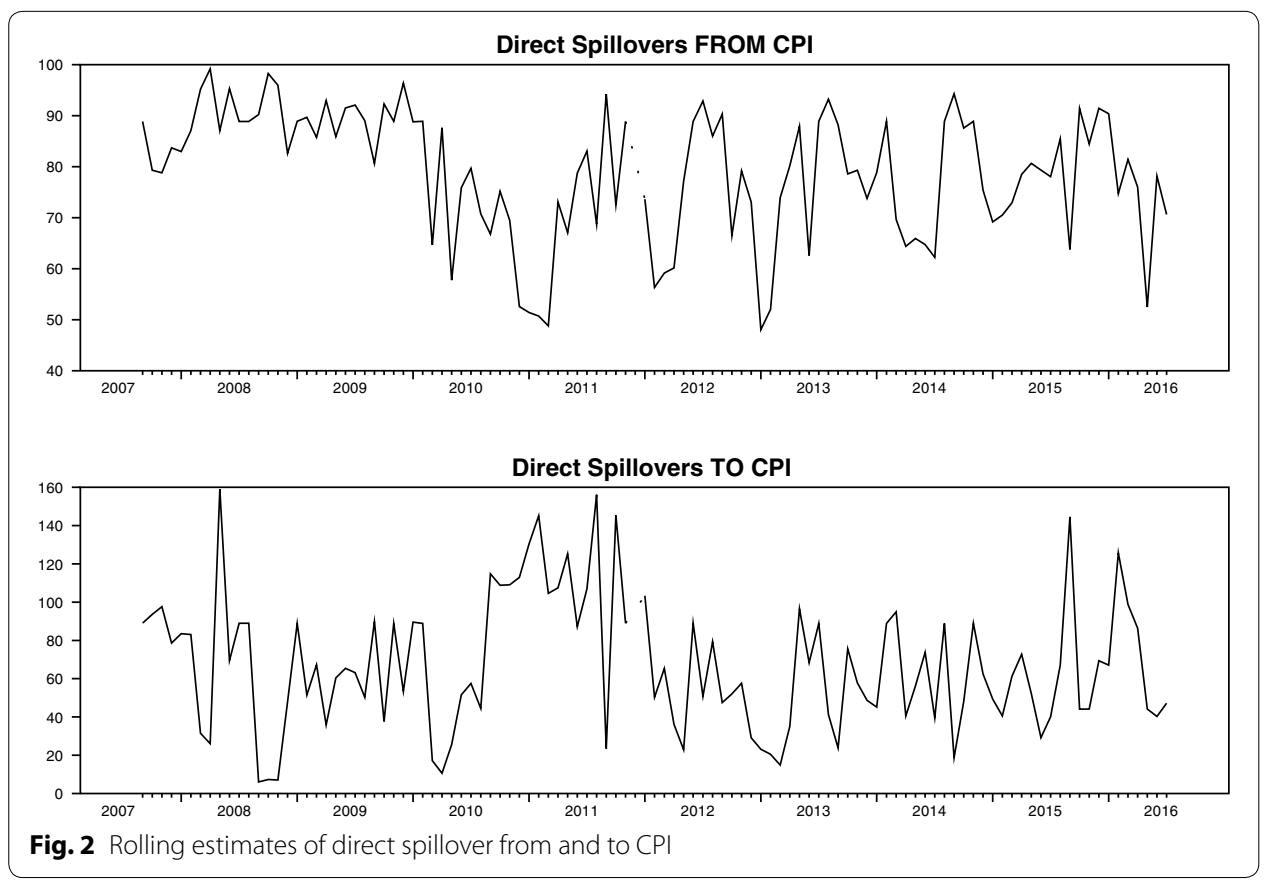




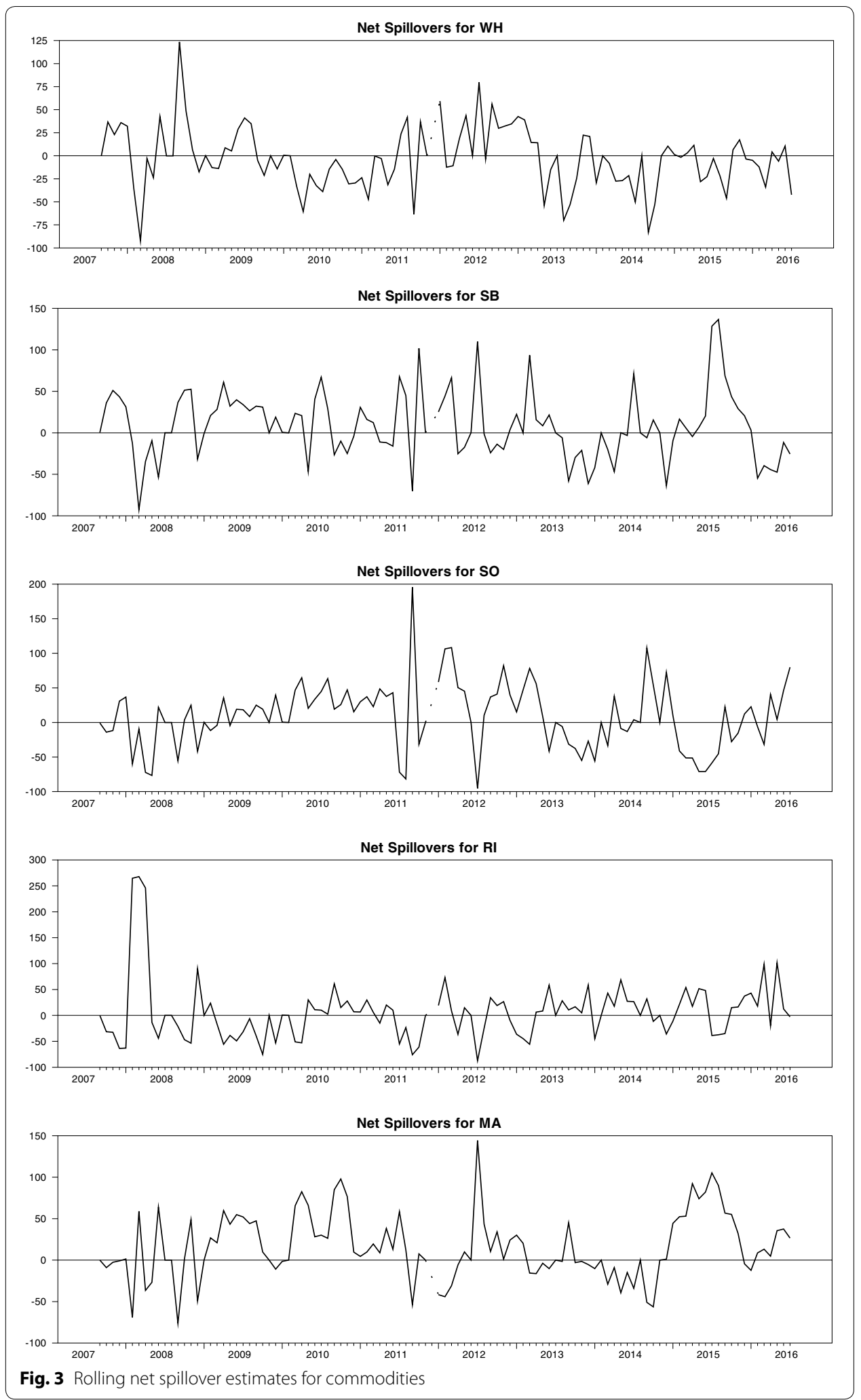



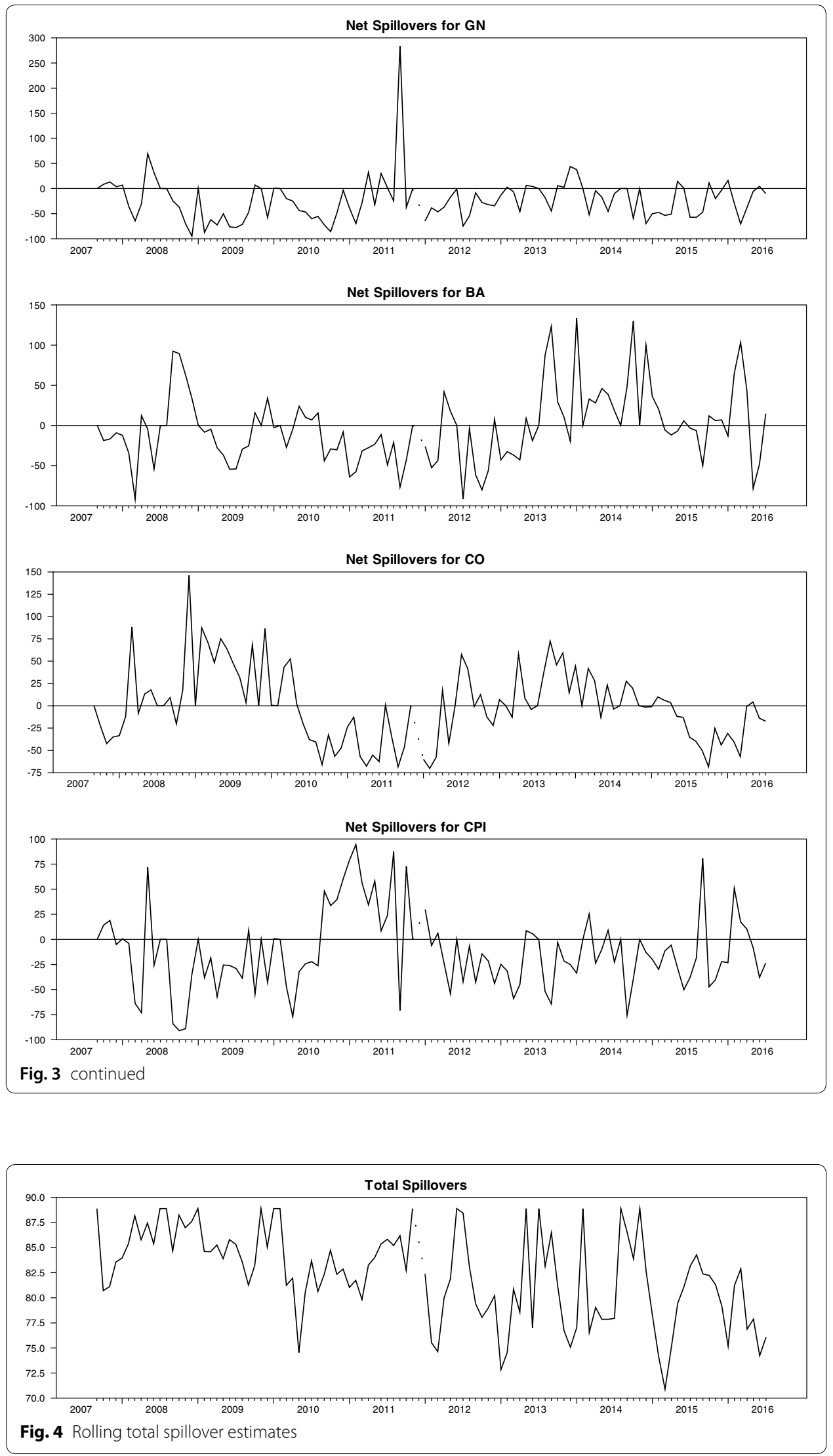
demand made the total spillovers hit a high of about $88 \%$ at that time. According to the National Bureau of Statistics, 2011 witnessed a high fluctuation of inflation and even this is evidenced in the agricultural commodities that saw the total spillovers fall to less than $80 \%$ as well as going as high as $90 \%$ in the very year. This being also an effect caused by the 2011 presidential elections. Around February 2012, the total spillovers fell to a dip of $75 \%$, this being a resultant effect of the protest against the unanticipated shock that arose from the removal of petroleum subsidy that occurred on January 1, 2012, a day dedicated for new year celebrations. The total spillovers relatively maintained stability around $80 \%$ before hitting another low of about $71 \%$ around March 2015, this being an obvious effect of the Nigeria presidential election at that time. The 2016 recession also saw a level of spillovers to the tune of $75 \%$.

\section{Conclusion}

We investigated the degree of interconnectedness between inflation and selected agricultural commodity prices in the face of the inflation-prone economy. Empirical analysis is based on newly developed forecast error variance decomposition framework of Diebold and Yilmaz (2012). The DY methodology offers the all-requisite spillovers indexes. In addition to the reported single fixed spillover index, the rolling window analysis is added to affirm the robustness and reliability of all estimations as well as it helps to capture secular and cyclical movement such as striking events and episodes for more engaging arguments.

Empirical results for our study span through 2006M1 to 2016M7 on a monthly frequency. The empirical analysis shows that the total spillover reveals an overwhelming high interdependency with $75 \%$ of the selected agricultural commodity prices and inflation over the investigated period considered is explained by spillover effects.

Our study further reveal that inflation, sorghum, soybeans, and wheat are net receivers while cocoa, barley, groundnut, maize, rice are net givers. These outcomes have inherent policy implication(s) for both end users and major actors in the agricultural commodity market for the case of Nigeria. Regarding the commodities that are net receivers, it implies that the spillover shock from those commodities are absorbed and not transmitted to the other commodities while the net givers are those that transmit spillover shocks when received. By and large, focus for policy-makers and government administrators in the agricultural domain is to gear concerted efforts to net givers as acclaimed by Diebold and Yilmaz $(2009,2012)$ "It is better to give than to receive". Based on the study's empirical outcome, there is need on the side of government officials to underpin the movement of price inflation and food price volatility. This action is critical for more pragmatic policy construction given that food/crop prices are highly vulnerable to shocks form fluctuation in price inflation. Thus, it pertinent for government administrators is to have workable knowledge on the mechanism of price dynamics among the crop/food commodity process and key macroeconomic indicators like price inflation, exchange rate among others. This is in bid to foster robust agricultural sector and by extension food security in African market that need to be urgently insulated from externalities, which dampens its optimal price stability. The policy-makers should also be cautious on the interconnectedness of the crop/food commodity prices. A large shock in one of the commodities due to supply or demand conditions has potential to easily 
spillover to other commodity prices. This is certainly more apparent across commodity groups that are close substitutes. As a way for further direction for other researchers, we propose that this study could be extended by exploring the agricultural commodity market spillover and other determinants like climate change and even oil price.

\section{Acknowledgements}

The author's gratitude is extended to the prospective editor(s) and reviewers who will/have spared time to guide toward a successful publication.

\section{Authors' contributions}

$M B$ was responsible for conceptual construction of the study's idea and empirical modelling and econometrics section. FVB handled the literature section and proofreading of the entire manuscript. Both authors read and approved the final manuscript.

\section{Funding}

I hereby declare that there is no form of funding received for this study.

\section{Availability of data and materials}

The data for this present studies are sourced from the DataStream of Thomson Reuters.

\section{Competing interests}

The authors declare that they have no competing interests.

\section{Author details}

${ }^{1}$ Eastern Mediterranean University, via Mersin 10, Famagusta, North Cyprus, Turkey. ${ }^{2}$ Faculty of Economics Administrative and Social Sciences, Istanbul Gelisim University, Istanbul, Turkey. ${ }^{3}$ Department of Accounting, Analysis and Audit, School of Economics and Management, South Ural State University, 76, Lenin Aven, Chelyabinsk 454080, Russia.

Received: 17 September 2019 Revised: 3 January 2020 Accepted: 8 January 2020

Published online: 27 January 2020

\section{References}

Abbott PC, Hurt C, Tyner WE (2009) What's driving food prices? March 2009 Update (No. 48495). Farm Foundation Akpan SB, Udoh EJ (2009) Relative price variability of grains and inflation rate movement in Nigeria. Glob J Agric Sci 8(2):147-151

Alene AD, Menkir A, Ajala SO, Badu-Apraku B, Olanrewaju AS, Manyong VM, Ndiaye A (2009) The economic and poverty impacts of maize research in West and Central Africa. Agric Econ 40(5):535-550

Alola AA, Alola UV (2018) Agricultural land usage and tourism impact on renewable energy consumption among Coastline Mediterranean Countries. Energy Environ 29(8):1438-1454

Alola UV, Cop S, Adewale Alola A (2019) The spillover effects of tourism receipts, political risk, real exchange rate, and trade indicators in Turkey. International Journal of Tourism Research

Baek J, Koo WW (2010) Analyzing factors affecting US food price inflation. Can J Agric Econ 58(3):303-320

Balcilar M, Chang S, Gupta R, Kasongo V, Kyei C (2014). The relationship between oil and agricultural commodity prices: a quantile causality approach. University of Pretoria, Department of Economics, Working Paper Series, 68

Diebold FX, Yilmaz K (2009) Measuring financial asset return and volatility spillovers, with application to global equity markets. Econ J 119(534):158-171

Diebold FX, Yilmaz K (2012) Better to give than to receive: predictive directional measurement of volatility spillovers. Int $J$ Forecast 28(1):57-66

Diebold FX, Yllmaz K (2014) On the network topology of variance decompositions: measuring the connectedness of financial firms. J Econom 182(1):119-134

Duncan AS, Kabundi A (2013) Domestic and foreign sources of volatility spillover to South African asset classes. Econ Model 31:566-573

FAO (2008) Soaring food prices: facts, perspectives, impacts and actions required. In: Proceedings of the high-level conference on World Food Security, Rome, 3-5 June 2008

Fasanya I, Akinbowale S (2019) Modelling the return and volatility spillovers of crude oil and food prices in Nigeria. Energy 169:186-205

Herndon CW (2008) The ethanolization of agriculture and the roles of agricultural economists. J Agric Appl Econ 40(2):403-414

Irz X, Niemi J, Xing L (2012) Determinants of food price inflation in Finland. Suomen Maataloustieteellisen Seuran Tiedote (28): $1-7$

Katusiime L (2019) Investigating spillover effects between foreign exchange rate volatility and commodity price volatility in Uganda. Economies 7:1. https://doi.org/10.3390/economies7010001

Koop G, Pesaran MH, Potter SM (1996) Impulse response analysis in nonlinear multivariate models. J Econometr 74(1):119-147

Lambert DK, Miljkovic D (2010) The sources of variability in US food prices. J Policy Model 32(2):210-222

Loening JL, Durevall D, Birru YA (2009) Inflation dynamics and food prices in an agricultural economy: the case of Ethiopia. The World Bank, Washington, DC 
Louzis DP (2012) Measuring return and volatility spillovers in Euro area financial markets. Bank of Greece Economic Research Department-Special Studies Division. Working paper series

Mitchell, D (2008) A note on rising food prices, policy research Working Paper No. 4682 Washington D.C., World Bank Nishimura Y, Tsutsui Y, Hirayama K (2015) Intraday return and volatility spillover mechanism from Chinese to Japanese stock market. J Jpn Int Econ 35:23-42

OECD (2008). Rising agricultural prices: causes, consequences and responses, OECD Policy Brief, August 2008

Pesaran HH, Shin Y (1998) Generalized impulse response analysis in linear multivariate models. Econ Lett 58(1):17-29

Rosegrant MW (2008) Biofuels and grain prices: impacts and policy responses. International Food Policy Research Institute, Washington, DC, pp 1-4

Salisu AA, Oyewole OJ, Fasanya IO (2018) Modelling return and volatility spillovers in global foreign exchange markets. J Inf Optim Sci 39(7):1417-1448

Trostle R (2008) Global agricultural supply and demand: factors contributing to the recent increase in food commodity prices. Economic Research Service Report WRS-0801. USDA

\section{Publisher's Note}

Springer Nature remains neutral with regard to jurisdictional claims in published maps and institutional affiliations.

Submit your manuscript to a SpringerOpen ${ }^{0}$ journal and benefit from:

- Convenient online submission

- Rigorous peer review

- Open access: articles freely available online

- High visibility within the field

- Retaining the copyright to your article

Submit your next manuscript at $\gg$ springeropen.com 